\title{
Articles
}

\section{Living in Cohousing Communities: Psychological Effects and Coping Strategies in Times of COVID-19}

\author{
Christian Schetsche ${ }^{\star}$ ab $\odot$, Luis Carlos Jaume ${ }^{\text {ab }} \odot$, Lucas Gago-Galvagno ${ }^{\text {ab }} \odot$, \\ Ángel Elgierab ${ }^{\mathrm{a}}$
}

[a] Instituto de Investigaciones, Facultad de Psicología, Universidad de Buenos Aires, Ciudad Autónoma de Buenos Aires, Argentina. [b] Laboratorio de Cognición y Políticas Públicas, Ciudad Autónoma de Buenos Aires, Argentina.

\begin{abstract}
The aim of this study was to compare a sample of residents in cohousing communities $(n=180)$ and inhabitants in traditional neighborhoods $(n=104)$. During the social isolation that was decreed by the German government due to the COVID-19 pandemic, data collection was carried out through the Internet. Psychological symptoms and coping strategies were measured, and their differences were investigated by multivariate analysis of variance (MANOVA). Results showed that residents in cohousing communities have lower levels of depressive, anxiety, compulsive and eating disorders, as well as less use of coping strategies which are based on emotional concealment, problem avoidance, and social withdrawal. Moreover, its inhabitants showed higher levels in the use of social support. It is concluded that living in a cohousing community favors, in comparison with life in traditional neighborhoods, the mental health of its inhabitants.
\end{abstract}

Keywords: cohousing communities, symptoms, coping, COVID-19

Interpersona, 2020, Vol. 14(2), 169-182, https://doi.org/10.5964/ijpr.v14i2.4257

Received: 2020-08-26. Accepted: 2020-10-23. Published (VoR): 2020-12-22.

*Corresponding author at: Universidad de Buenos Aires, Calle Plaza 1160, 1427 Villa Ortúzar, Ciudad Autónoma de Buenos Aires, Argentina. Tel: +54 9115913 4242, E-mail: christianschetsche@psi.uba.ar

This is an open access article distributed under the terms of the Creative Commons Attribution 4.0 International License, CC BY 4.0 (https://creativecommons.org/licenses/by/4.0/), which permits unrestricted use, distribution, and reproduction in any medium, provided the original work is properly cited.

\section{Cohousing Communities, Coping and Mental Health}

Cohousing is an alternative residential arrangement that consists of individual houses or apartments facing a common area and/or a common house for group meetings (Luscombe, 2019). This cooperative lifestyle originated in Denmark in the early 1970s and has spread throughout Scandinavia, Europe, and, more recently, the United States (Cummings \& Kropf, 2020). These communities did not emerge as a utopia to create a new way of living and modify social structures, but quite the opposite: Cohousing communities are a result of social changes that are based, among other factors, on the aging of the population and the modified role of women in society (Fedrowitz \& Gailing, 2003). Furthermore, their emergence can be interpreted as antithetical to the individualization process that is taking place (Andritzky, 1999). This could be because cohousing communities provide high degrees of autonomy and individual freedom and, simultaneously, the security that is offered by life in a traditional community (Berghäuser, 2013; Henckmann, 1999). Cohousing communities could be considered as extended families (Parke, 2017) and are characterized by substantially higher social support 
than that exchanged in traditional neighborhoods (Fedrowitz, 2016; Margolis \& Entin, 2011; Markle, Rodgers, Sanchez, \& Ballou, 2015).

Taking into account that social support also consists of one of the strategies used to cope with stressful situations, this circumstance leads us to analyze the transactional stress model of Lazarus and Folkman (1984). This model forms the theoretical basis for dealing with stress and reactions to it. When a situation is perceived as a threat or challenge, the individual makes an assessment of its physical, social, psychological, and coping resources and to what extent these can be used and implemented effectively to cope with stress. Coping strategies that are based on Lazarus' (1993) theory include differentiation between problem-oriented coping vs. emotion-oriented coping. Roth and Cohen (1986) divide coping strategies into the cognitive or behavioral processes of approach and avoidance. The approach, such as cognitive restructuring, leads to a deepening of the nature and origin of the stressor, so that its strategies represent an active process. Avoidance, such as denial, is passive (Beyer \& Lohaus, 2007). Another way of classifying consists of the differentiation between direct and indirect strategies. Direct strategies address the causes of stress, and indirect strategies attempt to change the intensity of stress or ignore emotions (Eschenbeck, Kohlmann, \& Lohaus, 2007; Griffith, Dubow, \& Ippolito, 2000; Klein-Heßling \& Lohaus, 2002). In this sense, Compas et al. (2017) highlight the strategies of emotional suppression, avoidance and denial, since these are related to higher levels of certain psychological symptoms.

Due to the existing causal relationship between stressful life events and depressive episodes (Duman, Aghajanian, Sanacora, \& Krystal, 2016), it is necessary to highlight the Global Burden of Disease which is carried out by the World Health Organization. It consists of the most comprehensive epidemiological study worldwide and describes the mortality and morbidity of the main diseases, injuries and risk factors for health. According to its first study in 1990, depression represented $10.7 \%$ of the Years Lost due to Disability (YLD) and was fourth in the Disability-Adjusted Life Years (DALY). In that year, depression was projected to occupy, in 2020, the second place of all DALY (Lopez \& Murray, 1998). As stated by the latest study by the World Health Organization (2018), mental and substance use disorders accounted for $20.61 \%$ of the YLD, thus being in the first place, ahead of diseases of the sensory organs with $13.24 \%$ and musculoskeletal diseases with $12.86 \%$.

\section{The COVID-19 Pandemic and Measures Taken by the German Government}

Since mid-March, the German government and the federal states have provided a variety of emergency aid to cushion the financial impact of the corona pandemic (Bundesagentur für Arbeit, 2020), and, on March 22, 2020, established certain restrictions: The population was encouraged to reduce their physical closeness in public spaces, and a minimum distance of $1.5 \mathrm{~m}$ to other people was imposed. Also, the gastronomic sector and the service sector corresponding to personal care were closed (Bundesregierung, 2020a). The government established, on April 15, 2020, a package for the easing of measures that allowed, among others, the re-opening of certain businesses (Bundesregierung, 2020b), and on April 30, 2020, the re-opening of playgrounds and religious and cultural institutions (Bundesregierung, 2020c).

Even though some federal states have imposed strong restrictions on leaving the home, it must be emphasized that the national government has not imposed quarantine per se, but measures to ensure social isolation. Because of this, it was decided to use the term Lockdown in this study, which is also the most widely used term in Germany. 


\section{Present Study: Possible Psychological Impacts of the Lockdown}

The psychological impacts of a quarantine make up a phenomenon that has been investigated numerous times and, following a study by Brooks et al. (2020), we can mention the duration of the quarantine, the fear of contagion, frustration and boredom, insufficient supplies and inadequate information on the development of the pandemic as the most important stressors that can arise during the quarantine. Furthermore, quarantine can have a negative impact on the economic situation and that can cause psychological disorders (Mihashi et al., 2009; Pellecchia, Crestani, Decroo, Van den Bergh, \& Al-Kourdi, 2015) and even anxiety symptoms after several months (Jeong et al., 2016). Looking now at the psychological impacts of Lockdown in Germany, we can see an increased sense of loneliness during the first 2 weeks (Buecker et al., 2020) and increased levels of anxiety and suicidal thoughts (Armbruster \& Klotzbücher, 2020).

In conclusion, it should be noted that the cohousing communities do not appear to have been the objective of a psychological study, neither in the context of the pandemic of COVID-19 nor outside it. Furthermore, the research that has been found maintains a sociological focus and points to the aforementioned social support. These investigations and their empirical evidence of greater social support in the cohousing communities formed the basis from which the present study aimed to explore the psychological impacts of the social isolation that was experienced during the COVID-19 pandemic.

The objective of the present study included the determination of the possible differences between residents of cohousing communities and people residing in traditional neighborhoods. To do so, we took into account the perceptions of the measures that the government took during the COVID-19 crisis, the coping strategies that were used during the Lockdown period, and their impact on certain psychological symptoms. The hypothesis was that residents in cohousing communities seek more social support and that such behavior has a positive effect on their mental health.

\section{Method}

\section{Sample and Procedure}

The non-probability sample was collected online in Germany, between April 14 and May 5, 2020. To ensure anonymous participation according to the General Data Protection Regulation that entered into force throughout the European Union on May 25, 2018, we used a Google Form that was created on a G-Suite account. This account guarantees, through the acceptance of the Data Processing Amendment the confidential treatment of information, including fingerprints that participants leave when they respond to a form that is located on the servers of the aforementioned company. To corroborate the satisfactory completion of the survey, a pilot test was conducted with 30 individuals.

The form was spread through the social network Facebook and, to access the sample of residents in cohousing communities, we consulted the website of the Trias Foundation, or Stiftung Trias in German, since it includes an index of approximately 1,000 cohousing communities and their corresponding contact details. Randomly, a total of 150 cohousing communities were chosen and contacted to inquire about their interest in participating in this study. Thirty five administrators committed to forwarding the form link to their adult residents so that they could participate voluntarily in the survey. 
Table 1 shows the sociodemographic data of the two samples. Out of 284 individuals that participated, 180 were residents of cohousing communities and 104 were residents of traditional neighborhoods. In the sample of residents in cohousing communities, the mean age was 55.14 years $(S D=13.67)$ and the mean age of the non-residents in cohousing communities was 39.48 years $(S D=11.74)$. Of all the participants who reside in cohousing communities, 123 were women (68.33\%) and 56 men $(31.11 \%)$ and, of the participants who do not reside in cohousing communities, 85 participants were female (81.73\%) and 16 male (15.38\%). 32 of the cohousing participants have received formal education for a range of 11 to 15 years $(17.78 \%)$ and 126 of them between 16 and 20 years $(70.00 \%)$. On the other hand, 40 residents in traditional neighborhoods have been through formal schooling between 11 and 15 years (38.46\%) and 51 between 16 and 20 years (49.04\%). The high percentages of participants who received formal education for more than 16 years can be considered as striking, since only $17.60 \%$ of the German population has graduate studies (Statistische Bundesamt, 2019).

Table 1

Sociodemographic Characteristics of the Two Samples

\begin{tabular}{|c|c|c|c|c|}
\hline \multirow[b]{2}{*}{ Characteristic } & \multicolumn{2}{|l|}{$n$} & \multicolumn{2}{|c|}{$M(S D)$} \\
\hline & Traditional neighborhoods & Cohousing & Traditional neighborhoods & Cohousing \\
\hline Age & 104 & 180 & $39.48(11.74)$ & $55.14(13.67)$ \\
\hline Years in living place & 104 & 180 & $7.86(8.03)$ & $8.68(6.98)$ \\
\hline \multicolumn{5}{|l|}{ Gender } \\
\hline Female & 85 & 123 & & \\
\hline Male & 16 & 56 & & \\
\hline Other & 3 & 1 & & \\
\hline \multicolumn{5}{|l|}{ Civil status } \\
\hline Single & 36 & 36 & & \\
\hline $\begin{array}{l}\text { Married/domestic } \\
\text { partner }\end{array}$ & 57 & 107 & & \\
\hline Divorced/separated & 11 & 34 & & \\
\hline Widow/er & 0 & 3 & & \\
\hline \multicolumn{5}{|l|}{ Education } \\
\hline $6-10$ years & 11 & 8 & & \\
\hline $11-15$ years & 40 & 32 & & \\
\hline $16-20$ years & 51 & 126 & & \\
\hline More than 20 years & 2 & 14 & & \\
\hline \multicolumn{5}{|c|}{ Number of people in the home } \\
\hline Alone & 26 & 54 & & \\
\hline 2 & 32 & 59 & & \\
\hline 3 & 21 & 18 & & \\
\hline 4 & 15 & 31 & & \\
\hline 5 & 8 & 6 & & \\
\hline More than 5 & 2 & 12 & & \\
\hline
\end{tabular}

\section{Instruments}

\section{Questions About the Lockdown}

Following various existing instruments that have been used to analyze public perceptions and the psychological impacts of the Lockdown (Brooks et al., 2020; Tracy, Rea, \& Upshur, 2009), a battery of seven questions 
has been developed. These questions are related to a possible change in work situation due to COVID-19 (Three-point Likert scale; 1 = Worse than before, 2 = No change, $3=$ Better than before), the number of days in Lockdown situation (scale), and the following five statements with a 5-point Likert scale (1 = Not at all, $2=$ Disagree, 3 = Neutral, 4 = Agree, $5=$ Totally agree): I comply with the government measures of the Lockdown. I am afraid of getting the coronavirus. I suffered from insufficient supply. I agree with the measures that the government took regarding the Lockdown. In my opinion, the incompliance of the Lockdown measures should be punished.

\section{ICD-10-Symptom Rating (ISR)}

We used the ICD-10-Symptom-Rating (ISR), which was developed by Tritt et al. (2009). The instrument has 29 items and six dimensions: Depression syndrome (4 items), anxiety syndrome (4 items), compulsive syndrome (3 items), somatization syndrome (3 items), and eating disorder (3 items). The sixth dimension is additional; it comprises 12 items to carry out a screening of other conditions, such as insomnia, sexuality, concentration problems, etc. Furthermore, the instrument offers an overall score that covers all symptoms. To answer, a 5-point Likert scale is used $(0=$ not true until $4=$ extremely true) and the internal consistencies are between .86 $\geq \alpha \geq$.78. In a study on the factor structure and psychometric properties of the ISR, Fischer, Tritt, Klapp, and Fliege (2010) concluded that the authors of this instrument were able to implement the intention of describing, through the selection of items that are closely oriented to the ICD-10, different and independent syndromes. In contrast to this, they highlight that other instruments, such as the SCL-90-R, have not been successful in obtaining these results in different samples, such as in a normal population and in another of psychosomatic patients (Hessel, Schumacher, Geyer, \& Brähler, 2001; Olsen, Mortensen, \& Bech, 2004; Rytilä-Manninen et al., 2016; Schmitz et al., 2000). According to Fischer et al. (2010), the ISR does allow specific diagnoses of disorders beyond a general stress factor that is not related to the symptoms. In this way, the authors conclude that the strongly empirical approach of the ICD-10 and the ISR possibly show an advantage over other instruments.

\section{Coping Strategies Inventory (CSI)}

The Coping Strategies Inventory (CSI), by Tobin, Holroyd, Reynolds, and Wigal (1989) comprises 72 items which represent eight subscales. These can be grouped into a second and third-order hierarchical factor structure. The third-order structure includes engagement and disengagement strategies, the second-order model problem engagement, emotion engagement, problem disengagement, and emotion disengagement. In the first order structure, we can find problem-solving and cognitive restructuring (problem engagement), express emotions and social support (emotion engagement), problem avoidance and wishful thinking (problem disengagement), self-criticism and social withdrawal (emotion disengagement). In its adaptation and Spanish validation, Cano García, Rodríguez Franco, and García Martínez (2007) were able to reduce the instrument to 40 items, of which five correspond to each of the eight first-order subscales. The instrument offers a 5-point Likert scale $(0=$ not at all to $4=$ totally) and has internal consistencies between $.89 \geq \alpha \geq .63$ but the authors were unable to reproduce the hierarchical structure that was proposed by Tobin et al. (1989).

In the present study, we used a German adaptation of the short version by Cano García et al. (2007). This German version showed the existence of an additional dimension that was called emotional concealment. The corresponding article to the German adaptation of the instrument is under editorial review. 


\section{Data Analysis}

To determine the internal consistencies, the Cronbach alphas $(\alpha)$ were calculated and the group differences were determined, on the one hand, through the Mann-Whitney- $U$ test (the effect size by Pearson's correlation coefficient) and, on the other hand, through the multivariate analysis of variances, or MANOVA, with Bonferroni's adjustment for several comparisons (the effect size by $\eta^{2}$ ). Extreme outliers were eliminated, homogeneity of variance was verified through the Levene test and, if necessary, Johnson or Box Cox transformations were performed. The partial correlations were quantified through the Pearson and Spearman coefficients. Only the transformations were carried out through the instruments provided by Hemmerich (2016a, 2016b) and, for all the other calculations described above, we used SPSS (Version 25) with the probability value $p \leq .05$.

\section{Results}

\section{Demographic Data and Their Group Differences}

We determined the need to use control variables, since apparent differences had been observed concerning the demographic data of both samples. Due to the presence of data that did not follow a normal distribution and/or data with an ordinal nature, several Mann-Whitney- $U$ tests were performed (Dinneen \& Blakesley, 1973). As far as educational levels was concerned, the distribution of both groups differed, Kolmogorov-Smirnov $p$ $<.05$ and a statistically significant difference could be found between residents of cohousing communities $\left(M_{\text {Rank }}=157.82\right)$ and non-residents in these communities $\left(M_{\text {Rank }}=115.99\right), U=6603.00, Z=-4.803, p<.001$, $r=.285$. Regarding age, the distribution of both groups did not differ, Kolmogorov-Smirnov $p=.304$ and a statistically significant difference was found between residents of cohousing communities $(M d n=54.50)$ and non-residents $(M d n=39.00), U=3691.00, Z=-8.505, p<.001, r=.505$. In the case of number of years living in the place, the distribution of both groups differed, Kolmogorov-Smirnov $p<.05$, and a statistically significant difference was found between residents of cohousing communities $\left(M_{\text {Rank }}=149.99\right)$ and non-residents $\left(M_{\text {Rank }}=\right.$ 129.54), $U=8012.000, Z=-2.028, p=.042, r=.120$.

Due to the above mentioned reasons, age, number of years living in the place and educational level were used as control variables to determine group differences concerning all the dimensions that were analyzed below.

\section{Lockdown Data and Its Group Differences}

As can be seen in Table 2, no significant differences could be found concerning the questions about the Lockdown.

Table 2

Statistical Summary of Questions Related to Lockdown

\begin{tabular}{|c|c|c|c|c|c|c|c|}
\hline \multirow[b]{2}{*}{ Measure } & \multicolumn{2}{|c|}{ Cohousing communities ${ }^{a}$} & \multicolumn{2}{|c|}{ Traditional neighborhood $^{\mathbf{b}}$} & \multirow[b]{2}{*}{$\boldsymbol{F}$} & \multirow[b]{2}{*}{$p$} & \multirow[b]{2}{*}{$\eta^{2}$} \\
\hline & $M$ & $S D$ & $M$ & $S D$ & & & \\
\hline Lock1: Change in employment situation & 1.79 & 0.423 & 1.68 & 0.508 & 0.597 & .441 & .002 \\
\hline Lock2: Days under Lockdown & 34.21 & 10.779 & 30.47 & 8.437 & 3.680 & .056 & .013 \\
\hline Lock3: Lockdown compliance & 4.21 & 0.753 & 4.17 & 0.875 & 1.679 & .196 & .006 \\
\hline Lock4: Fear of contagion & 2.54 & 1.043 & 2.35 & 1.050 & 0.001 & .975 & .000 \\
\hline
\end{tabular}




\begin{tabular}{|c|c|c|c|c|c|c|c|}
\hline \multirow[b]{2}{*}{ Measure } & \multicolumn{2}{|c|}{ Cohousing communities $^{a}$} & \multicolumn{2}{|c|}{ Traditional neighborhood $^{\mathrm{b}}$} & \multirow[b]{2}{*}{$\boldsymbol{F}$} & \multirow[b]{2}{*}{$p$} & \multirow[b]{2}{*}{$\eta^{2}$} \\
\hline & $M$ & $S D$ & $M$ & $S D$ & & & \\
\hline Lock5: Insufficient supply & 1.18 & 0.454 & 1.37 & 0.725 & 0.868 & .352 & .003 \\
\hline Lock6: Appropriate measure & 3.71 & 1.267 & 4.04 & 0.991 & 1.402 & .237 & .005 \\
\hline Lock7: Non-compliance punishment & 2.80 & 1.085 & 3.10 & 1.211 & 0.907 & .342 & .003 \\
\hline
\end{tabular}

Note. Alpha $=.05$.

${ }^{\mathrm{a}} n=180 .{ }^{\mathrm{b}} n=104$.

\section{Psychological Influences, Coping Strategies and Their Group Differences}

We calculated Cronbach's alphas for the reliability analysis. Although some internal consistencies were below those which were obtained in their original studies, we can observe in Table 3 that all the values are between moderate and high (Hinton, 2014).

Table 3

Statistical Summary of Psychometric Instruments

\begin{tabular}{|c|c|c|c|c|c|c|c|c|c|}
\hline \multirow[b]{2}{*}{ Measure } & \multirow[b]{2}{*}{$\alpha$} & \multicolumn{2}{|c|}{$\begin{array}{l}\text { (I) Cohousing } \\
\text { communities }^{a}\end{array}$} & \multicolumn{2}{|c|}{$\begin{array}{l}\text { (J) Traditional } \\
\text { neighborhoods }^{\mathrm{b}}\end{array}$} & \multirow{2}{*}{$\begin{array}{c}\text { Mean } \\
\text { difference }^{c} \\
(I-J)\end{array}$} & \multirow[b]{2}{*}{$F$} & \multirow[b]{2}{*}{$p^{c}$} & \multirow[b]{2}{*}{$n^{2}$} \\
\hline & & $M$ & $S D$ & $M$ & $S D$ & & & & \\
\hline ISR depression J & .87 & -0.096 & 0.889 & 0.245 & 0.998 & $-0.318^{*}$ & 5.121 & .024 & .019 \\
\hline ISR anxiety J & .82 & -0.243 & 0.948 & 0.164 & 1.03 & $-0.395^{*}$ & 7.001 & .009 & .026 \\
\hline ISR compulsion & .68 & 0.672 & 0.794 & 0.939 & 0.871 & $-0.295^{\star}$ & 5.651 & .018 & .021 \\
\hline ISR somatization & .75 & 0.395 & 0.566 & 0.442 & 0.631 & -0.070 & 0.608 & .436 & .002 \\
\hline ISR eating disorder & .75 & 0.774 & 0.821 & 1.020 & 0.968 & $-0.317^{*}$ & 5.628 & .018 & .021 \\
\hline ISR overall score & .91 & 0.708 & 0.458 & 0.930 & 0.545 & $-0.222^{*}$ & 8.832 & .003 & .032 \\
\hline CSI problem-solving & .69 & 2.556 & 0.568 & 2.541 & 0.698 & -0.087 & 0.855 & .356 & .003 \\
\hline CSI cognitive restructuration & .68 & 2.414 & 0.683 & 2.484 & 0.614 & -0.012 & 0.014 & .905 & .000 \\
\hline CSI express emotions & .79 & 1.524 & 0.729 & 1.676 & 0.842 & 0.052 & 0.208 & .649 & .001 \\
\hline CSI social support & .74 & 2.605 & 0.753 & 2.318 & 0.807 & $0.315^{*}$ & 7.259 & .008 & .027 \\
\hline CSI problem avoidance & .69 & 1.053 & 0.634 & 1.353 & 0.650 & $-0.292^{*}$ & 8.922 & .003 & .032 \\
\hline CSI wishful thinking & .70 & 1.993 & 0.832 & 2.233 & 0.783 & -0.180 & 2.108 & .148 & .008 \\
\hline CSI self-criticism BC & .86 & 0.806 & 0.379 & 0.848 & 0.414 & -0.025 & 0.177 & .674 & .001 \\
\hline CSI social withdrawal & .59 & 1.928 & 0.966 & 2.357 & 1.111 & $-0.366^{*}$ & 5.629 & .018 & .021 \\
\hline CSI emotional concealment & .85 & 1.151 & 0.889 & 1.439 & 0.900 & $-0.285^{*}$ & 4.385 & .037 & .016 \\
\hline CSI PE & .69 & 2.485 & 0.479 & 2.512 & 0.502 & -0.049 & 0.441 & .507 & .002 \\
\hline CSI EE & .78 & 2.064 & 0.592 & 1.997 & 0.681 & 0.184 & 3.860 & .050 & .014 \\
\hline CSI PD & .68 & 1.523 & 0.544 & 1.793 & 0.508 & $-0.236^{*}$ & 8.501 & .004 & .031 \\
\hline CSI ED & .79 & 1.171 & 0.539 & 1.398 & 0.614 & $-0.241^{*}$ & 7.804 & .006 & .028 \\
\hline CSIE & .79 & 2.275 & 0.428 & 2.255 & 0.502 & 0.067 & 0.953 & .330 & .004 \\
\hline CSI D & .81 & 1.347 & 0.451 & 1.595 & 0.465 & $-0.238^{*}$ & 11.825 & .001 & .042 \\
\hline
\end{tabular}

Note. ISR = ICD-10-Symptom Rating; CSI = Coping Strategies Inventory; PE = problem engagement; EE = emotion engagement; PD = problem disengagement; $E D=$ emotion disengagement; $E=$ engagement; $D=$ disengagement.

${ }^{\mathrm{a}} n=174 .{ }^{\mathrm{b}} n=98 .{ }^{\mathrm{c}}$ Adjustment for multiple comparison: Bonferroni; J, $M$ and $S D$ after a Johnson transformation; $\mathrm{BC}, M$ and $S D$ after a Box Cox transformation.

${ }^{*} p<.05$ (based on estimated marginal means).

We found 12 outliers that were more than three standard deviations from the mean value, so these values had to be eliminated from the sample. Next, we performed the Levene test and its results showed that ISR 
depression $(p=.040)$, ISR anxiety $(p=.008)$ and CSI self-criticism $(p=.002)$ did not have homogeneity of variances. To comply with this requirement, Johnson transformations were performed on ISR depression ( $p$ $=.690)$ and ISR anxiety $(p=.689)$, and a Box Cox transformation on CSI self-criticism $(p=.314)$, since the Johnson transformation could not improve the homogeneity of variances in this dimension.

Regarding the significant differences we found between residents in cohousing communities and habitants in traditional neighborhoods, we can highlight the following dimensions: ISR depression, ISR anxiety, ISR compulsion, ISR eating disorder, ISR overall score, CSI social support, CSI problem avoidance, CSI social withdrawal, CSI emotional concealment, CSI problem disengagement, CSI emotion disengagement and CSI disengagement.

\section{Correlations}

In Table 4, we can see the table of partial correlations between the dimensions that showed significant differences between residents of cohousing communities and people who reside in traditional neighborhoods. The upper right axis represents the values of the residents in traditional neighborhoods and the lower-left axis the values of the inhabitants in cohousing communities. An increased number of significant correlations have been found, so only the highest correlations between symptoms and coping strategies will be highlighted. Likewise, it should be noted that the correlations have been more pronounced in the cohousing sample, which could be due to its larger size. Of the first-order coping strategies, CSI emotional concealment must be highlighted, since it had the strongest correlations with the symptoms that were analyzed in the present study.

Table 4

Partial Pearson Correlations Between the Dimensions With Significant Differences

\begin{tabular}{|c|c|c|c|c|c|c|c|c|c|c|c|c|}
\hline \multirow[b]{2}{*}{ Cohousing } & \multicolumn{12}{|c|}{ Traditional neighborhoods } \\
\hline & 1. & 2. & 3. & 4. & 5. & 6. & 7. & 8. & 9. & 10. & 11. & 12. \\
\hline 1. ISR DEP & 1 & $.447^{* *}$ & $.569^{* *}$ & $.399^{* *}$ & $.834^{* *}$ & -.037 & .037 & $.201^{*}$ & $.204^{*}$ & $.268^{* *}$ & $.307^{* *}$ & $.352^{* *}$ \\
\hline 2. ISR ANX & $.415^{\star *}$ & 1 & $.520^{* *}$ & .085 & $.695^{\star *}$ & -.040 & .034 & $.208^{*}$ & .132 & $.202^{*}$ & $.252^{*}$ & $.279^{* *}$ \\
\hline 3. ISR COM & $.347^{* *}$ & $.427^{\star *}$ & 1 & .098 & $.783^{* *}$ & -.010 & -.053 & .188 & .088 & .156 & $.241^{*}$ & $.246^{*}$ \\
\hline 4. ISR EAT & $.349^{* *}$ & .131 & $.256^{\star *}$ & 1 & $.440^{* *}$ & -.025 & .073 & .003 & .159 & .173 & .142 & .190 \\
\hline 5. ISR OS & $.749^{* *}$ & $.685^{\star *}$ & $.673^{* *}$ & $.566^{* *}$ & 1 & -.029 & .075 & $.220^{*}$ & $.205^{*}$ & $.275^{\star *}$ & $.314^{* *}$ & $.361^{* *}$ \\
\hline 6. CSI SSU & $-.183^{*}$ & -.046 & -.060 & -.093 & -.145 & 1 & -.079 & $-.516^{\star *}$ & $-.328^{* *}$ & .040 & -.161 & -.085 \\
\hline 7. CSI PAV & .129 & -.064 & .103 & $.177^{*}$ & .098 & -.126 & 1 & -.064 & $.299^{\star *}$ & $.670^{* *}$ & $.340^{* *}$ & $.595^{\star *}$ \\
\hline 8. CSI SWI & $.225^{\star *}$ & $.189^{*}$ & .127 & .095 & $.220^{* *}$ & $-.500^{\star *}$ & -.083 & 1 & .101 & .033 & $.247^{*}$ & .183 \\
\hline 9. CSI ECO & $.323^{\star *}$ & $.168^{*}$ & $.273^{\star *}$ & $.225^{\star \star}$ & $.331^{\star *}$ & $-.508^{\star *}$ & $.330^{* *}$ & $.260^{\star *}$ & 1 & $.260^{*}$ & $.630^{* *}$ & $.563^{\star *}$ \\
\hline 10. CSI PD & $.331^{* *}$ & $.201^{* *}$ & .119 & $.198^{*}$ & $.294^{\star *}$ & -.043 & $.648^{\star *}$ & .072 & $.358^{* *}$ & 1 & $.347 .^{* *}$ & $.780^{\star *}$ \\
\hline 11. CSI ED & $.361^{* *}$ & $.196^{*}$ & $.296^{\star *}$ & $.328^{* *}$ & $.405^{\star *}$ & $-.399^{\star *}$ & $.282^{\star *}$ & $.314^{* *}$ & $.775^{\star \star}$ & $.391^{* *}$ & 1 & $.857^{* *}$ \\
\hline 12. CSI D & $.415^{\star \star}$ & $.238^{\star *}$ & $.248^{* *}$ & $.315^{\star \star}$ & $.418^{\star \star}$ & $-.264^{* *}$ & $.559^{* *}$ & $.231^{\star \star}$ & $.677^{* *}$ & $.836^{\star *}$ & $.832^{* \star}$ & 1 \\
\hline
\end{tabular}

Note. ISR = ICD-10-Symptom Rating; DEP = depression; ANX = anxiety; COM = compulsion; EAT = eating disorder; OS = overall

score; CSI = Coping Strategies Inventory; SSU = social support, PAV = problem avoidance; SWI = social withdrawal; ECO = emotional

concealment; $\mathrm{PD}=$ problem disengagement; $\mathrm{ED}=$ emotion disengagement; $\mathrm{D}=$ disengagement.

${ }^{*} p<.05$ (bilateral). ${ }^{* *} p<.01$ (bilateral).

In the sample of inhabitants in traditional neighborhoods, the most striking correlations have been ISR depression and CSI emotion disengagement, $r=.307, p<.001$, ISR depression and CSI disengagement, $r=.352$, $p<.001$, ISR overall score and CSI emotional disengagement, $r=.314, p<.001$, ISR depression and CSI 
disengagement, $r=.361, p<.001$. In the sample of residents in cohousing communities, the most striking correlations have been ISR depression and CSI emotional concealment, $r=.323, p<.001$, ISR depression and CSI problem disengagement, $r=.331, p<.001$, ISR depression and CSI emotion disengagement, $r=.361$, $p<.001$, ISR depression and CSI disengagement, $r=.415, p<.001$, ISR eating disorder and CSI emotion disengagement, $r=.328, p<.001$, ISR eating disorder and CSI disengagement, $r=.315, p<.001$, ISR overall score and CSI emotional concealment, $r=.331, p<.001$, ISR overall score and CSI emotion disengagement, $r$ $=.405, p<.001$, ISR overall score and CSI disengagement, $r=.418, p<.001$.

As can be seen in Table 5, there are also significant correlations between the Lockdown questions and the different psychological dimensions in which significant differences have been found between residents in cohousing communities and residents in traditional neighborhoods.

Correlations will be shown without contrasting places of residence because no significant differences could be found in the Lockdown questions. The change towards a more positive work situation (due to the Lockdown) has a positive correlation with the perception that the government took appropriate measures, $r=.244, p$ $<.001$. On the other hand, it is worth noting the fear of contagion, since it has a moderate correlation with compliance with the Lockdown measures, $r=.369, p<.001$, with the perception that the measures the government took are appropriate, $r=.396, p<.001$, with the perception that non-compliance with the measures should be punished, $r=.295, p<.001$, with ISR anxiety, $r=.264, p<.001$ and with CSI problem avoidance, $r=.202, p$ $<.001$. Due to the correlation between these four questions about the Lockdown, it was determined that they could be used as a scalar dimension since their internal consistency has been $\alpha=.728$.

Table 5

Spearman's Correlations Between Dimensions With Significant Differences and Questions Related to Lockdown

\begin{tabular}{|c|c|c|c|c|c|c|c|}
\hline Measure & 1. & 2. & 3. & 4. & 5. & 6. & 7. \\
\hline 1. Lock1: Change in employment situation & 1 & & & & & & \\
\hline 2. Lock2: Days under Lockdown & -.008 & 1 & & & & & \\
\hline 3. Lock3: Lockdown compliance & .047 & .107 & 1 & & & & \\
\hline 4. Lock4: Fear of contagion & $.129^{*}$ & .094 & $.369^{* *}$ & 1 & & & \\
\hline 5. Lock5: Insufficient supply & .023 & .006 & $.155^{\star}$ & $.176^{\star *}$ & 1 & & \\
\hline 6. Lock6: Appropriate measure & $.244^{* *}$ & .062 & $.412^{\star \star}$ & $.396^{* *}$ & $.136^{\star}$ & 1 & \\
\hline 7. Lock7: Non-compliance punishment & .079 & -.005 & $.406^{\star *}$ & $.295^{\star *}$ & $.185^{\star *}$ & $.497^{* *}$ & 1 \\
\hline 8. ISR depression & -.086 & -.042 & -.044 & $.126^{*}$ & $.145^{\star}$ & -.072 & .011 \\
\hline 9. ISR anxiety & -.044 & -.033 & .047 & $.264^{\star *}$ & .058 & -.032 & .031 \\
\hline 10. ISR compulsion & -.018 & .002 & -.044 & .064 & .046 & -.058 & -.110 \\
\hline 11. ISR eating disorder & -.028 & .020 & -.099 & .030 & .056 & -.033 & -.034 \\
\hline 12. ISR overall score & -.084 & -.022 & -.044 & $.169^{* *}$ & $.133^{*}$ & -.057 & -.024 \\
\hline 13. CSI social support & -.053 & .055 & -.118 & .043 & -.085 & .036 & -.097 \\
\hline 14. CSI problem avoidance & -.068 & -.050 & $-.190^{\star *}$ & $-.202^{\star *}$ & .005 & $-.147^{*}$ & -.022 \\
\hline 15. CSI social withdrawal & .012 & .061 & $.328^{* *}$ & $.219^{* *}$ & $.213^{\star *}$ & $.222^{* *}$ & $.238^{\star *}$ \\
\hline 16. CSI emotional concealment & .036 & -.020 & -.022 & .055 & $.141^{*}$ & .043 & .113 \\
\hline 17. CSI PD & .005 & -.101 & -.111 & .020 & .064 & -.078 & .050 \\
\hline 18. CSI ED & .040 & -.006 & -.007 & .104 & $.177^{\star \star}$ & .071 & $.130^{*}$ \\
\hline 19. CSI D & .025 & -.069 & -.062 & .061 & $.141^{*}$ & .005 & .111 \\
\hline
\end{tabular}




\section{Discussion}

With the objective of determining the existence of differences between the inhabitants of cohousing communities and residents of traditional neighborhoods, 21 dimensions were evaluated. In 13 of these dimensions, significant differences were found, thus evidencing that the sample of inhabitants in cohousing communities had lower levels of depressive, anxiety, compulsive, and eating disorders.

Also, we were able to find more use of social support in cohousing communities which is consistent with previous research (Markle et al., 2015; Parke, 2017). Likewise, it is striking that, among the residents in cohousing communities, the most used strategy was precisely the search for social support when, among the residents in traditional neighborhoods, the most used strategy was problem-solving. Social support as a source of greater well-being is a topic that has been investigated in-depth and, in this context, Cohen and Wills (1985) have already been able to show that the mere existence of social support provides greater well-being. In addition to the aforementioned main effect, the same authors also showed the buffering effect of social support, since it is considered as a protective factor that works in combination with stress and balances, or moderates the effect that stressors have on the psychological situation.

In the present study, it has been possible to go one step further towards understanding the functioning of cohousing communities since not only significant differences have been found in the use of coping strategies based on social support, but also a significantly less use of disengagement strategies. We must highlight this finding for two reasons: On the one hand, because the significant differences had a larger effect size in these latter dimensions and, on the other hand, it is precisely these disengagement strategies that have the greatest correlation with the symptoms which were evaluated in the present investigation. Numerous previous studies have demonstrated the existence of significant correlations between inadequate coping strategies and certain symptoms (Evans et al., 2015; García-Alberca et al., 2012) and, although it cannot be stated whether the symptoms described in the present study constitute a cause of the isolation or whether they have already existed before the Lockdown began, we can highlight the fact that, in cohousing communities, these inadequate strategies were used at a lesser extent.

Regarding first-order coping strategies, emotional concealment should be highlighted as a key strategy of the present study. As it had the highest correlations with the analyzed symptoms, it is important to note that social support had the highest negative correlation with emotional concealment.

Taking into account that, so far, cohousing communities have been investigated from a sociological point of view and with a focus on existing social support, it is questionable what relationship could exist between each of the coping strategies when these are in an environment whose nature itself is characterized by social support. Precisely at this point lies a certain limitation of the present study, since the existing correlations indicate a link between adequate coping strategies and inadequate coping strategies and also a correlation between inadequate coping strategies and certain psychological symptoms, but its causal relationships could not be determined. Likewise, it is important to bear in mind that, in the present study, non-probability sampling was carried out and that the sample size can be considered relatively small, making the generalization of its results difficult.

Analyzing the questions related to the Lockdown itself, we were unable to find significant differences between cohousing residents and habitants of traditional neighborhoods. Even so, it is highlighted that the fear of 
contagion, compliance with the Lockdown measures, the perception that the government took appropriate measures, and the perception that non-compliance should be punished have a significant correlation with anxiety, this being one of the dimensions that showed to be the least outstanding in the sample of cohousing residents.

\section{Conclusion}

The present study was able to demonstrate that the residents of cohousing communities have, from various points of view, a better state of mental health and, also, that they use fewer amounts of disengagement coping strategies, so they seem to have better tools to also cope with the difficult situations associated with social isolation due to the Lockdown. Although these results are favorable, there is also a need for further studies that examine whether coexistence in a cohousing community can operate as a moderator of stress, thus helping to improve the mental health of its inhabitants. This inquiry may be clarified through future research that delves into the study of cohousing communities and, through mediation analyzes, assesses a possible causal relationship between different coping strategies and psychological symptoms.

\section{Funding}

The authors have no funding to report.

\section{Competing Interests}

The authors have declared that no competing interests exist.

\section{Acknowledgments}

The authors have no support to report.

\section{References}

Andritzky, M. (1999). Balance zwischen Heim und Welt. Wohnweisen und Lebensstile von 1945 bis heute. In I. Flagge

(Ed.), Geschichte des Wohnens. Band 5: 1945 bis heute Aufbau Neubau Umbau (pp. 615-686). Stuttgart, Germany: Deutsche Verlags-Anstalt.

Armbruster, S., \& Klotzbücher, V. (2020). Lost in lockdown? COVID-19, social distancing, and mental health in Germany

(No. 2020-04). Retrieved from http://hdl.handle.net/10419/218885

Berghäuser, M. (2013). Fragen und Antworten zum gemeinschaftlichen Wohnen: Gemeinschaftliches Wohnen. Darmstad, Germany: Schader-Stiftung.

Beyer, A., \& Lohaus, A. (2007). Konzepte zur Stressentstehung und Stressbewältigung im Kindes-und Jugendalter. In A. Lohaus (Ed.), Stress und Stressbewältigung im Kindes-und Jugendalter (pp. 11-27). Göttingen, Germany: Hogrefe Göttingen.

Brooks, S. K., Webster, R. K., Smith, L. E., Woodland, L., Wessely, S., Greenberg, N., \& Rubin, G. J. (2020). The psychological impact of quarantine and how to reduce it: Rapid review of the evidence. SSRN Electronic Journal, 395, 912-920. https://doi.org/10.2139/ssrn.3532534 
Buecker, S., Horstmann, K. T., Krasko, J., Kritzler, S., Terwiel, S., Kaiser, T., \& Luhmann, M. (2020). Changes in daily loneliness during the first four weeks of the Covid-19 lockdown in Germany. https://doi.org/10.31234/osf.io/ytkx9

Bundesagentur für Arbeit. (2020). Übersicht Soforthilfen zur Abfederung der finanziellen Auswirkungen während der Corona-Pandemie. Retrieved from

https://www.arbeitsagentur.de/datei/uebersicht-soforthilfeprogramme-corona_ba146398.pdf

Bundesregierung. (2020a). Erweiterung der beschlossenen Leitlinien zur Beschränkung sozialer Kontakte: Besprechung der Bundeskanzlerin mit den Regierungschefinnen und Regierungschefs der Länder am 22 März 2020. Retrieved from https://www.bundesregierung.de/resource/blob/975226/1733246/e6d6ae0e89a7ffea1ebf6f32cf472736/2020-03-22-mpkdata.pdf?download=1

Bundesregierung. (2020b). Telefonschaltkonferenz der Bundeskanzlerin mit den Regierungschefinnen und Regierungschefs der Länder am 15 April 2020. Retrieved from https://www.bundesregierung.de/resource/blob/973812/1744226/bcf47533c99dc84216eded8772e803d4/2020-04-15beschluss-bund-laender-data.pdf?download=1

Bundesregierung. (2020c). Telefonschaltkonferenz der Bundeskanzlerin mit den Regierungschefinnen und Regierungschefs der Länder am 30 April 2020. Retrieved from https://www.bundesregierung.de/resource/blob/975226/1749804/353e4b4c77a4d9a724347ccb688d3558/2020-04-30beschluss-bund-laender-data.pdf?download=1

Cano García, F. J., Rodríguez Franco, L., \& García Martínez, J. (2007). Adaptación española del Inventario de Estrategias de Afrontamiento. Actas Españolas de Psiquiatría, 35(1), 29-39.

Cohen, S., \& Wills, T. A. (1985). Stress, social support, and the buffering hypothesis. Psychological Bulletin, 98(2), 310-357. https://doi.org/10.1037/0033-2909.98.2.310

Compas, B. E., Jaser, S. S., Bettis, A. H., Watson, K. H., Gruhn, M. A., Dunbar, J. P., . . Thigpen, J. C. (2017). Coping, emotion regulation, and psychopathology in childhood and adolescence: A meta-analysis and narrative review. Psychological Bulletin, 143(9), 939-991. https://doi.org/10.1037/bul0000110

Cummings, S., \& Kropf, N. P. (2020). Senior cohousing. https://doi.org/10.1007/978-3-030-25362-2

Dinneen, L. C., \& Blakesley, B. C. (1973). Algorithm AS 62: A generator for the sampling distribution of the Mann-Whitney U statistic. Applied Statistics, 22(2), 269-273. https://doi.org/10.2307/2346934

Duman, R. S., Aghajanian, G. K., Sanacora, G., \& Krystal, J. H. (2016). Synaptic plasticity and depression: New insights from stress and rapid-acting antidepressants. Nature Medicine, 22(3), 238-249. https://doi.org/10.1038/nm.4050

Eschenbeck, H., Kohlmann, C.-W., \& Lohaus, A. (2007). Gender differences in coping strategies in children and adolescents. Journal of Individual Differences, 28(1), 18-26. https://doi.org/10.1027/1614-0001.28.1.18

Evans, L. D., Kouros, C., Frankel, S. A., McCauley, E., Diamond, G. S., Schloredt, K. A., \& Garber, J. (2015). Longitudinal relations between stress and depressive symptoms in youth: Coping as a mediator. Journal of Abnormal Child Psychology, 43(2), 355-368. https://doi.org/10.1007/s10802-014-9906-5

Fedrowitz, M. (2016). Gemeinschaftliches Wohnen—Stand und Entwicklung in Deutschland. Nachrichten Der ARL, 1, 9-12. 
Fedrowitz, M., \& Gailing, L. (2003). Zusammen wohnen—Gemeinschaftliche Wohnprojekte als Strategie sozialer und ökologischer Stadtentwicklung. Dortmund, Germany: Institut für Raumplanung, Fakultät für Raumplanung Universität Dortmund.

Fischer, H. F., Tritt, K., Klapp, B. F., \& Fliege, H. (2010). Faktorstruktur und psychometrische Eigenschaften des ICD-10Symptom-Rating (ISR) an Stichproben psychosomatischer Patienten. PPmP_Psychotherapie Psychosomatik Medizinische Psychologie, 60(08), 307-315. https://doi.org/10.1055/s-0029-1214419

García-Alberca, J. M., Cruz, B., Lara, J. P., Garrido, V., Lara, A., \& Gris, E. (2012). Anxiety and depression are associated with coping strategies in caregivers of Alzheimer's disease patients: Results from the MÁLAGA-AD study. International Psychogeriatrics, 24(8), 1325-1334. https://doi.org/10.1017/S1041610211002948

Griffith, M. A., Dubow, E. F., \& Ippolito, M. F. (2000). Developmental and cross-situational differences in adolescents' coping strategies. Journal of Youth and Adolescence, 29(2), 183-204. https://doi.org/10.1023/A:1005104632102

Hemmerich, W. (2016a). StatistikGuru: Box-Cox powertransformation berechnen. Retrieved from https://statistikguru.de/rechner/box-cox.html

Hemmerich, W. (2016b). StatistikGuru: Johnson transformation berechnen. Retrieved from https://statistikguru.de/rechner/johnson-transformation-berechnen.html

Henckmann, A. (1999). Aufbruch in ein gemeinsames Altern. https://doi.org/10.1007/978-3-322-93292-1

Hessel, A., Schumacher, J., Geyer, M., \& Brähler, E. (2001). Symptom-Checkliste SCL-90-R: Testtheoretische Überprüfung und Normierung. Diagnostica, 47(1), 27-39. https://doi.org/10.1026//0012-1924.47.1.27

Hinton, P. (2014). SPSS explained. London, United Kingdom: Routledge. https://doi.org/10.4324/9781315797298

Jeong, H., Yim, H. W., Song, Y.-J., Ki, M., Min, J.-A., Cho, J., \& Chae, J.-H. (2016). Mental health status of people isolated due to Middle East Respiratory Syndrome. Epidemiology and Health, 38, Article e2016048. https://doi.org/10.4178/epih.e2016048

Klein-Heßling, J., \& Lohaus, A. (2002). Zur situationalen Angemessenheit der Bewältigung von Alltagsbelastungen im Kindes-und Jugendalter. Kindheit Und Entwicklung: Zeitschrift Für Klinische Kinderpsychologie, 11(1), 29-37. https://doi.org/10.1026//0942-5403.11.1.29

Lazarus, R. S. (1993). Coping theory and research: Past, present, and future. Psychosomatic Medicine, 55(3), 234-247. https://doi.org/10.1097/00006842-199305000-00002

Lazarus, R. S., \& Folkman, S. (1984). Stress, appraisal, and coping. New York, NY, USA: Springer.

Lopez, A. D., \& Murray, C. C. J. L. (1998). The global burden of disease, 1990-2020. Nature Medicine, 4(11), 1241-1243. https://doi.org/10.1038/3218

Luscombe, G. (2019). Cohousing. In D. Gu \& M. E. Dupre (Eds.), Encyclopedia of gerontology and population aging (pp. 13). https://doi.org/10.1007/978-3-319-69892-2_738-1

Margolis, D., \& Entin, D. (2011). Report on survey of cohousing communities 2011. Retrieved from http://oldsite.cohousing.org/node/2023 
Markle, E. A., Rodgers, R., Sanchez, W., \& Ballou, M. (2015). Social support in the cohousing model of community: A mixed-methods analysis. Community Development, 46(5), 616-631. https://doi.org/10.1080/15575330.2015.1086400

Mihashi, M., Otsubo, Y., Yinjuan, X., Nagatomi, K., Hoshiko, M., \& Ishitake, T. (2009). Predictive factors of psychological disorder development during recovery following SARS outbreak. Health Psychology, 28(1), 91-100. https://doi.org/10.1037/a0013674

Olsen, L. R., Mortensen, E. L., \& Bech, P. (2004). The SCL-90 and SCL-90R versions validated by item response models in a Danish community sample. Acta Psychiatrica Scandinavica, 110(3), 225-229. https://doi.org/10.1111/j.1600-0447.2004.00399.x

Parke, R. D. (2017). Family psychology: Past and future reflections on the field. Journal of Family Psychology, 31(3), 257-260. https://doi.org/10.1037/fam0000318

Pellecchia, U., Crestani, R., Decroo, T., Van den Bergh, R., \& Al-Kourdi, Y. (2015). Social consequences of Ebola containment measures in Liberia. PLOS ONE, 10(12), Article Article e0143036.

https://doi.org/10.1371/journal.pone.0143036

Roth, S., \& Cohen, L. J. (1986). Approach, avoidance, and coping with stress. American Psychologist, 41(7), 813-819. https://doi.org/10.1037/0003-066X.41.7.813

Rytilä-Manninen, M., Fröjd, S., Haravuori, H., Lindberg, N., Marttunen, M., Kettunen, K., \& Therman, S. (2016). Psychometric properties of the Symptom Checklist-90 in adolescent psychiatric inpatients and age- and gendermatched community youth. Child and Adolescent Psychiatry and Mental Health, 10(23), 1-12. https://doi.org/10.1186/s13034-016-0111-x

Schmitz, N., Hartkamp, N., Kiuse, J., Franke, G. H., Reister, G., \& Tress, W. (2000). The symptom check-list-90-R (SCL-90R): A German validation study. Quality of Life Research, 9(2), 185-193. https://doi.org/10.1023/A:1008931926181

Statistische Bundesamt. (2019). Deutsches Statistisches Bundesamt: Bevölkerung nach Bildungsabschluss in Deutschland. Retrieved from https://www.destatis.de/DE/Themen/Gesellschaft-Umwelt/Bildung-Forschung-Kultur/Bildungsstand/Tabellen/ bildungsabschluss.html\#fussnote-1-104098

Tobin, D. L., Holroyd, K. A., Reynolds, R. V., \& Wigal, J. K. (1989). The hierarchical factor structure of the coping strategies inventory. Cognitive Therapy and Research, 13(4), 343-361. https://doi.org/10.1007/BF01173478

Tracy, C. S., Rea, E., \& Upshur, R. E. (2009). Public perceptions of quarantine: Community-based telephone survey following an infectious disease outbreak. BMC Public Health, 9(470), 1-8. https://doi.org/10.1186/1471-2458-9-470

Tritt, K., Zaudig, M., Klapp, B., Loew, T., Söllner, W., \& von Heymann, F. (2009). Kennwerte des Fragebogens ICD-10Symptom-Rating (ISR). PPmP_Psychotherapie Psychosomatik Medizinische Psychologie, 59(02), $409-418$. https://doi.org/10.1055/s-0029-1208202

World Health Organization. (2018). Global health estimates 2016: Disease burden by cause, age, sex, by country and by region, 2000-2016. Retrieved from https://www.who.int/healthinfo/global_burden_disease/estimates/en/index1.html 